\title{
AGGLUTINATION OF HAEMOLYTIC STREPTOCOCCI (GROUP A) IN SERUM FROM PATIENTS WITH RHEUMATOID ARTHRITIS
}

\author{
BY
}

\author{
K. KALBAK
}

Copenhagen

\section{From the State Serum Institute, Copenhagen *}

The theory of a streptococcal causation of rheumatoid arthritis continues to be of great importance, and since it was first advanced it has been supported by serological and bacteriological investigations, including agglutination tests, more especially in the United States. Table 1 summarizes a number of these investigations.

The writer (Kalbak, 1946) obtained 79 per cent. of positive reactions among rheumatoid arthritis patients. In the control material the positives represented a very low percentage. In the same year Cecil and de Gara reported finding positive agglutination reactions in 60 per cent. of 268 patients with rheumatoid arthritis. The number of positive reactions among scarlatina patients was only 25 per cent., and in a control material there were none, or only very few. In their opinion the test was more often positive in patients with a severe joint affection, whereas the reaction became weaker and gradually quite negative as the disease improved or was cured.

Edström and Winblad (1947) had 76 per cent. of positive reactions among fifty patients with rheumatoid arthritis. They claimed that the reaction did not become positive until four or six months after the commencement of the streptococcal infection. Using a somewhat altered technique, Thulin (1947) obtained over 90 per cent. of positive reactions, and Hedlund (1947) 55 per cent., among patients with rheumatoid arthritis. The article by Angevine and others (1942) should also be consulted.

The conclusions to be drawn from these investigations appear to be:

1. The agglutination test is best made with haemolytic streptococci of Lancefield's Group A.

2. Among polyarthritis patients there are between 50 and 75 per cent. positive agglutination reactions.

3. The percentage of positives in the control materials is very low. 


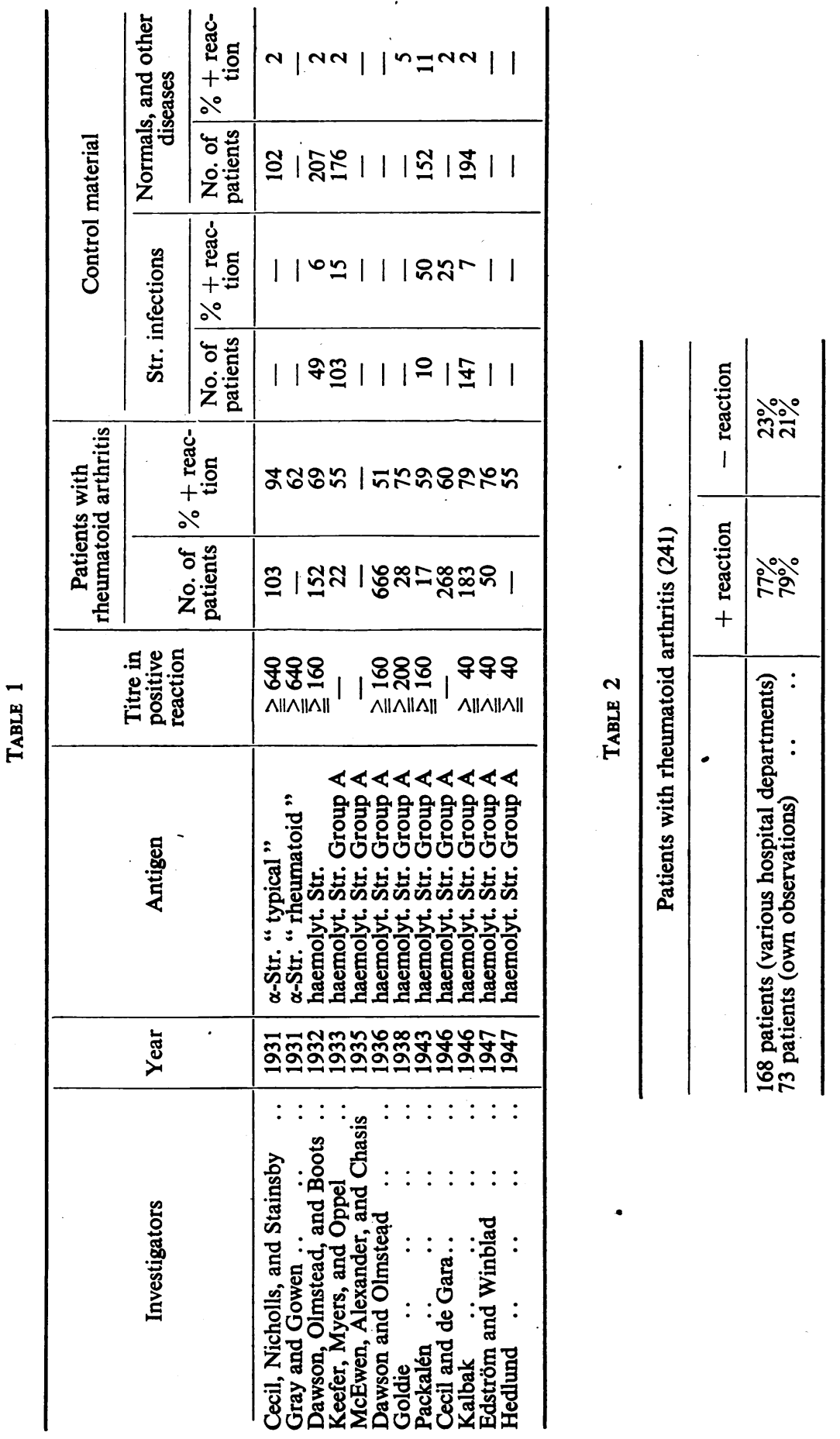




\section{The Author's Investigations}

\section{TECHNIQUE}

My technique is based mainly upon that of Dawson and Olmstead, though with certain modifications, whereby the reaction has become rather more specific; the positive percentage among rheumatoid arthritis patients has increased, whereas the control material still gives a very low percentage of positives.

A suitable streptococcus is selected, that is, belonging to Group A (though Groups $\mathbf{C}$ and $\mathrm{G}$ may also be employed). Groups A, C, and G are the so-called human-pathogenic haemolytic streptococci, and it is these that form streptolysin. The type is a subordinate matter. The important point is that the bacterium grows diffusely with no tendency to agglutinate spontaneously.

Culture proceeds in a medium which experience shows will give diffuse growth. The composition of the broth is as follows:

To $750 \mathrm{~g}$. minced beef add 1.5 litres of mains water, and leave overnight in the refrigerator $\left(4^{\circ} \mathrm{C}\right.$.). Next day, boil the mixture for 15 minutes, then filter through filter-paper, and adjust the $p \mathrm{H}$ to 8.0 by adding 'sodium hydroxide. Boil again for 30 minutes.' To $500 \mathrm{ml}$. of this meat extract add $5 \mathrm{~g}$. peptone (Bacto- or Orthanapeptone) and $2.5 \mathrm{~g}$. sodium chloride. Boil again. Adjust the $p \mathrm{H}$ to 8.0 by adding sodium hydroxide. Filter into a sterile flask, then autoclave for 20 minutes at $120^{\circ} \mathrm{C}$. After autoclaving the $p \mathrm{H}$ must be about 7.6 to $7 \cdot 8$.

The broth is thus rather thin without glucose. The small quantity of sodium chloride is supposed to have a bearing on the diffuse growth of the bacteria. The kind of peptone is very important in getting a successful result. One requirement is that the streptococci grow very slowly out into the broth, so that even after about 14 hours' growth it is only diffusely turbid. If they grow quickly and strongly, the culture seems to be less suitable as an antigen. Possibly. the optimal period of growth varies somewhat for the various strains, but it seems to be more than 10 hours and less than 15.

Having secured a suitable growth, the living culture is used as the antigen and added direct to the serum dilutions. Heat-killed culture can be employed $\left(56^{\circ} \mathrm{C}\right.$. for 30 minutes), but this process increases the chances of spontaneous agglutination, so it is better to work with living culture.

The patient's serum is diluted with 0.3 per cent. sodium chloride to $1: 10-1: 20$, etc., to $1: 1,280$, in eight tubes in all. The same amount of living culture is added, so that the final dilutions are $1: 20-1: 40$, etc., to $1: 2,560$. After careful shaking, the tubes are left for two hours in a waterbath at $52^{\circ} \mathrm{C}$. for agglutination. They are then left overnight in the refrigerator at $4^{\circ} \mathrm{C}$., and read next day.

Reading is macroscopic. The tubes should be lightly shaken. The culture will have precipitated somewhat as a result of the long period in the refrigerator. If the reaction is negative the sediment shakes up just as diffusely as the original culture. If it is positive the sediment shakes up in clumps consisting of agglutinated streptococci. The strength of the reaction is indicated in four degrees:

4. Large coherent discs which are difficult to shake to pieces. This reaction is very rare. The supernatant fluid is clear. Signified as ++++ .

3. The sediment shakes up in coarse clumps. The fluid clear. Signified as +++ .

2. The sediment shakes up in medium and small clumps. The fluid clear. Signified as ++ .

1. The sediment shakes up in very small "woolly" clumps. The liquid is turbid, signifying that agglutination is only partial. Signified as + .

$\mathbf{0}$. The sediment shakes up diffuse. No agglutination. Signified as $\mathbf{0}$.

Negative reactions are: all cases where the agglutination in the first tube is 0 or 1 , regardless of the degree of agglutination in the next tubes, for instance: (1) 00000000 , (2) 11000000, and 
(3) 01210000 . It is open to discussion whether agglutination such as (2) should be described as a doubtful positive reaction. In the present work this latter form of reaction is called negative. As strength 2 in the first tube is almost always followed by the weaker strength 1 in the next tube, this means that there will scarcely ever be a positive reaction with a titre of 20 , and that therefore the weakest positive reaction will almost always be $1: 40$. The most frequent positive reaction is, for example, 33210000 .

I have made a number of tests of the living culture as the antigen, especially when compared with trypsin-treated culture and after washing with 0.9 per cent. sodium chloride. As the living culture will not agglutinate after washing, as all types of haemolytic streptococci can be agglutinated in the serum of polyarthritis patients, and as there is a distinct difference between agglutination with living culture and that with trypsin-treated culture (in which the group antigen is particularly prominent), $I$ believe that the antigen which governs the agglutination in serum from rheumatoid arthritis is a very labile antigen lying on the surface (capsular antigen?) which is neither a type nor a group antigen and which is associated with the human-pathogenic haemolytic streptococci (Groups A, C, and G).

\section{The Clinical Material}

The clinical material comprises a total of 1,141 cases, of which 241 were patients with rheumatoid arthritis, and 900 were control cases.

Rheumatoid arthritis patients.-The 241 patients were made up of 168 from whom samples of sera were sent to the State Serum Institute by various hospital departments, and 73 cases of my own. The findings are shown in Table 2, from which it will be seen that in a series consisting of patients with rheumatoid arthritis there were about 80 per cent. positive agglutination reactions and about 20 per cent. negative.

Especially interesting are my own 15 observations with a negative agglutination test. Among them are four typical cases of rheumatoid arthritis in the active phase, with raised sedimentation rate. The fact must therefore be established before going any further that a negative agglutination test occurs in completely* typical cases of rheumatoid arthritis, clinically indistinguishable from the other cases with positive reaction. My other negative cases include two cases of polyarthritis psoriatica - the only ones in the series. Two patients with negative agglutination tests had a normal erythrocyte sedimentation rate, and in another patient with a negative test the joint pains had just begun and were very slight. Two had very old joint affections, of sixteen and twenty-eight years' duration respectively. In both cases the affection was inactive, with complete ankylosis of the joints but otherwise without particular discomfort.

One patient had a normal erythrocyte sedimentation rate and very severe epilepsy. Moreover, she underwent hysterectomy three years ago for severe metrorrhagia. The joint affection began a year later and was not quite typical. There was a pronounced tendency to contracture, and she was operated in both palms for very severe Dupuytren's contracture. The joint affection must be described as atypical.

Two other patients had atypical polyarthritis. One closely resembled sclerodermia. The joints had hardly any capsular swelling, but the skin was very tight and the fingers had a tendency to contracture. The other patient may have 
had arthritis urica, for the serum uric acid was constantly high and the joint changes were chiefly localized to the principal joints, whereas there were no changes in the fingers.

The cases of rheumatoid arthritis with a positive agglutination test were on the whole typical. It would, therefore, seem justifiable to conclude that among the polyarthritis cases with a negative agglutination test there are relatively more of an atypical nature, with a normal sedimentation rate, with psoriatic polyarthritis, and with old and inactive or very early disease.

Concerning the patients with a positive reaction, four interesting questions arise:

1. Is there a connexion between the titre and the clinical course?

2. At what stage in the disease does the reaction become positive?

3. At what stage does the reaction become negative again?

4. What effect on the reaction has the treatment (especially gold treatment)?

The observations are rather limited in number as yet, and therefore the figures in Table 3 must be taken with some reserve.

TABLE 3

TITRE VALUES

\begin{tabular}{l|c|c|c|c|c|c}
\hline & \multicolumn{3}{|c|}{ Agglutination titres } & \\
\cline { 2 - 7 } & $1: 40$ & $1: 80$ & $1: 160$ & $1: 320$ & $1: 640$ & \\
\hline $\begin{array}{l}\text { No. of patients with chronic polyarthritis and } \\
\text { positive agglutination reaction. }\end{array}$ & $\begin{array}{c}6 \\
(10 \%)\end{array}$ & $\begin{array}{c}18 \\
(31 \%)\end{array}$ & $\begin{array}{c}19 \\
(31 \%)\end{array}$ & $\begin{array}{c}11 \\
(19 \%)\end{array}$ & $\begin{array}{c}4 \\
(9 \%)\end{array}$ & 58 patients \\
$\begin{array}{l}\text { No. of patients in control material with } \\
\text { positive agglutination reaction. }\end{array}$ & 13 & 22 & 7 & 2 & - & 44 patients \\
$(30 \%)$ & $(50 \%)$ & $(15 \%)$ & $(5 \%)$ & - & \\
\hline
\end{tabular}

This table shows that most polyarthritis patients have an agglutination titre of $1: 80$ and $1: 160$, but that a considerable number reach a value of $1: 320$ and $1: 640$. In the control material the titre of the positive reactions is distinctly lower on an average, 80 per cent. of them being $1: 40$ and $1: 80$, and there are none at $1: 640$. The evidence thus is that the strongest reactions occur in patients with rheumatoid arthritis. As far as can be judged it will probably also be found that patients with the most severe lesions have the highest titre.

Patients treated with gold were also tested. Within the period of observation (three to four months) there was no sign of any marked change in the titre. In no case did the titre fall to normal values (negative reaction).

We do not yet know definitely if the reaction can become negative. The probability is that it can, because the test was negative in two old wholly inactive cases in the third phase; but as we do not know whether the reactions of these patients were previously positive, this is simply. a not improbable hypothesis; 
Coburn, too, claims to have observed that in acute rheumatic fever when the joint affection becomes quiescent the reaction becomes negative.

Another question of particular interest is when the reaction becomes positive. Here again to say anything definite would be bold. Apparently some considerable time elapses before it happens-seemingly longer than the two or three weeks it takes for the antistreptolysin reaction to become positive, and in fact for most seroreactions. Edström and Winblad (1947) have reported on some interesting observations suggesting that agglutinin scarcely forms until four to six months after the onset of the disease. This will detract from the diagnostic value of the reaction; but by repeating the test at intervals of about a month there is a chance of observing that a negative reaction becomes positive.

\section{The Control Material}

The control material consisted of 900 pecple.

(1) Sixty-four normal people volunteered as blood donors. One had a positive reaction (1.5 per cent.).

(2) There were 130 patients with various medical ambulant affections, arbitrarily selected from the blood samples sent in for Wassermann tests from the Medical Policlinic of the Rigshospital. Only one of these had a positive reaction.

(3) The streptococcal infection group consisted of patients infected with haemolytic and nonhaemolytic streptococci. There were 20 with scarlatina in the third or fourth week of the attack, and none gave a positive reaction. Next, 38 sera were selected with an especially high antistreptolysin titre $(\underline{800)}$ ). None of these gave a positive reaction either. But among 100 sera from rheumatic fever patients there were 10 per cent. with a positive reaction.

Actually, the only definite infection with non-haemolytic streptococci is the subacute bacterial endocarditis (endocarditis lenta). Nine cases, all verified by repeated positive blood cultures with Strep. viridans demonstrated in each case, gave a negative agglutination reaction. This strengthens the supposition that the reaction is specific to haemolytic streptococci. If the reaction were positive in the case of streptococcal infections in general, we should certainly expect it to be positive in a disease like endocarditis lenta, in which there is bacteriaemia and the streptococci occur freely in the blood stream.

(4) As examples of other infectious joint affections I have included 18 cases of gonococcal polyarthritis. None of the blood samples was positive.

(5) A group of patients with "various rheumatic affections" but excluding rheumatoid arthritis consisted of 41 from the Department of Physical Medicine of the Kommunehospital,

TABLE 4

CONTROL PATIENTS (900)

\begin{tabular}{|c|c|c|c|}
\hline Diagnosis & No. of patients & $\begin{array}{l}\text { Positive aggl. } \\
\text { reaction }\end{array}$ & $\begin{array}{l}\text { Negative aggl. } \\
\text { reaction }\end{array}$ \\
\hline 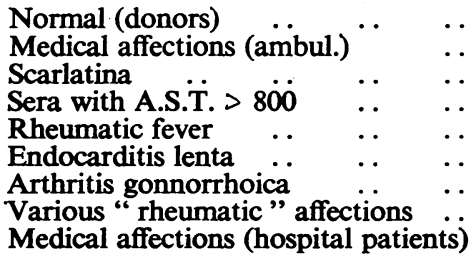 & $\begin{array}{r}64 \\
130 \\
20 \\
18 \\
100 \\
9 \\
18 \\
41 \\
500\end{array}$ & $\begin{array}{l}1 \cdot 5 \% \\
0 \cdot 8 \% \\
0 \\
0 \\
10 \% \\
0 \\
0 \\
15 \% \\
7 \%\end{array}$ & $\begin{array}{l}98 \cdot 5 \% \\
99 \cdot 2 \% \\
100 \% \\
100 \% \\
90 \% \\
100 \% \\
100 \% \\
85 \% \\
93 \%\end{array}$ \\
\hline
\end{tabular}


comprising patients with arthrosis, rheumatic fever, sciatica, poliomyelitis, etc. In this group the reaction was positive in 15 per cent.

Thus it is among rheumatic fever patients and in this latter group that we find the highest agglutination percentage in the control material (see Table 4). As the last-named group includes rheumatic fever patients, this is presumably the explanation of the relatively high percentage of positive reactions.

(6) Finally, there is a group of hospitalized patients suffering from various medical affections, all in the Nørre Hospital. A total of 533 patients were systematically tested with this reaction. Of these, 33 had chronic polyarthritis, and these were accounted for when dealing with this group of patients. Of the remaining 500, a positive agglutination reaction was obtained from 36 ( 7 per cent.).

The diagnoses in this group cover a wide variety of diseases, but among the patients with a positive reaction one kind of disease is particularly represented: chronic inflammation in the respiratory tract. Of the 36 patients, 14 had chronic infections of this kind (chronic bronchitis, sometimes combined with asthma, unspecific lung infiltration, bronchiectasis, chronic sinusitis, chronic tonsillitis, etc.). In addition, there were 5 cases of cardiac insufficiency with lung stasis. The remaining 17 cases represent various diagnosis.

\section{The Immuno-biological Importance of the Agglutination Reaction}

The aetiological value of the reaction depends exclusively upon whether or not the agglutination is specific, that is, whether it is induced by streptococcal antigens or not. If it is unspecific, it is presumably caused by other antigenic substances occurring in patients with rheumatoid arthritis and possibly not necessarily of a bacterial nature.

The two main arguments against the reaction being a specific reaction to haemolytic streptococci are: (1) the apparent contradistinction between the antistreptolysin reaction and the agglutination reaction; and (2) the fact that it has not yet been possible with certainty to cultivate haemolytic streptococci from patients with rheumatoid arthritis.

If we examine the antistreptolysin titre in a large series of patients with rheumatoid arthritis we find that its distribution is exactly the same as in a normal material (Kalbak, 1944, 1946), that is to say, we find only about 10 per cent. of increased values. Thus the antistreptolysin reaction alone provides no basis for attributing the infection of these patients to haemolytic streptococci. Then how shall we explain that haemolytic streptococci agglutinate in the serum of about 80 per cent. of these patients? Surely both reactions are an expression of an infection by these bacteria? Should not both reactions be positive if there were really an infection by streptococci?

This argument is only apparently right. Both reactions are an expression of an infection with haemolytic streptococci, it is true, but each represents two different mechanisms of immunity. The one (the antistreptolysin reaction) is an antitoxic reaction; the other (the agglutination reaction) is an antibacterial reaction. This means that first and foremost the antistreptolysin reaction is a reflection of the function of the streptococci, their toxin formation in the organism, whereas the agglutination reaction merely expresses the presence of the bacterium itself, dead or living. 
Thus the antistreptolysin reaction depends upon two factors: (1) The presence of haemolytic streptococci, and (2) that these streptococci are living and capable of producing toxin (streptolysin). The agglutination reaction depends only on there being haemolytic streptococci in the organism-it seems immaterial whether they are living and highly virulent, greatly attenuated, or even dead. Thus we may quite well imagine the possibility that the streptococci become attenuated so much that their production of toxin ceases and the antistreptolysin reaction becomes negative, whilst the agglutinins are still being produced and cause a positive agglutination reaction. If we compare this with Edström and Winblad's observation that the formation of agglutinin only becomes perceptible after the disease has lasted from four to six months, this will explain the apparent contradictions. Theoretically there is actually no contradiction when the antistreptolysin reaction is negative and the agglutination reaction positive.

TABLE 5

\begin{tabular}{c|c|c|c}
\hline Mode of immunization & $\begin{array}{c}\text { Antitoxin } \\
\text { antitoxic anti- } \\
\text { bodies }\end{array}$ & $\begin{array}{c}\text { Agglutinin } \\
\text { antibacterial } \\
\text { antibodies }\end{array}$ & $\begin{array}{c}\text { Hypothetic } \\
\text { occurrence in } \\
\text { clinic }\end{array}$ \\
\hline $\begin{array}{c}\text { Intravenous injection of streptolysin } \\
\text { (toxin). }\end{array}$ & +++ & 0 & No occurrence \\
$\begin{array}{c}\text { Intravenous injection of killed strepto- } \\
\text { cocci. }\end{array}$ & 0 & $(+) 0$ & +++ \\
$\begin{array}{c}\text { Intravenous injection of living strepto- } \\
\text { cocci }\end{array}$ & +++ & $(+) 0$ & $\begin{array}{c}\text { Chronic poly- } \\
\text { arthritis? } \\
\text { Subcutaneous injection of living } \\
\text { streptococci suspended in semi-fluid } \\
\text { agar (artificial focus). }\end{array}$ \\
\hline
\end{tabular}

These views may also be supported experimentally (Table 5): (1) When pure toxin is injected intravenously into rabbits (streptolysin, for example), there is a formation of considerable quantities of antitoxin (antistreptolysin). No agglutinin forms, because there are no corpuscular antigens. (2) With the intravenous injection of killed haemolytic streptococci into rabbits no antistreptolysin forms, as streptolysin is formed only by living streptococci. But there is an abundant production of agglutinins, because their formation depends only on the presence of the bacterial body (living or dead). (3) Agglutinins are also formed by the intravenous injection of living haemolytic streptococci into rabbits. Antitoxin formation seems less certain, probably depending upon whether the bacteria have the chance to settle in the organism, perhaps in one or more foci, to produce streptolysin there. The antistreptolysin titre often rises, but in many cases it does not. (4) With the establishment of a focus (subcutaneous injection of living haemolytic streptococci suspended in semi-fluid agar), streptolysin forms in it and there is an increase in the antistreptolysin titre. In this case the bacteria are mostly confined to the spot and the formation of agglutinin seems to be more uncertain.

If we transfer these four possibilities to the bedside-by comparing them with 
the occurrence of antibodies in infections caused by haemolytic streptococci, we shall see that hitherto-known streptococcal infections must chiefly be placed under group 4. They are sore throat and its attendant affections, scarlatina, glomerulonephritis, rheumatic fever, chronic tonsillitis, and the like with increased formation of antistreptolysin and with an absence or only a very low production of agglutinin. Groups 2 and 3, on the other hand, come closer to the serological conditions found in rheumatoid arthritis.

Edström and Winblad by means of monthly tests followed the antistreptolysin titre and the agglutination reaction of patients suffering from rheumatoid arthritis. For example, a patient was hospitalized with symptoms of rheumatic fever, and during the subsequent six months developed the picture of a typical rheumatoid arthritis-a course that is not uncommon. It was possible to show how the antistreptolysin titre, which was high at the onset of the disease, fell in the course of the next four months towards normal values. At the onset the agglutination test was negative, but after five months it became positive and thereafter rose to high values $(1: 640)$. This is a very important observation. It has gradually become generally recognized that an increased antistreptolysin is due to infection by haemolytic streptococci; when a positive agglutination reaction follows immediately afterwards, it is a very strong argument that this reaction, too, is caused by haemolytic streptococci-that in other words the reaction is specific to these bacteria.

The agglutination reaction is associated with the human-pathogenic haemolytic streptococci-groups A, C, and G (and possibly certain streptococci of group E). Other groups do not react. Other streptococci, Strep. viridans, enterococci, and other bacteria on the whole, do not seem to react with sera from patients with rheumatoid arthritis.

Starting with the clinical observations, and repeated agglutination tests on individual patients, the following hypothesis may be advanced: $A$ positive agglutination reaction is an expression of a chronic infection with haemolytic streptococci. If the antistreptolysin titre is simultaneously negative, the indication is that the streptococci have lost their power of producing toxin and are of low virulence.

The probability is that the antigen (agglutinogen) which governs and assists in the agglutination reaction is situated on the outermost surface of the streptococci and is of a labile nature.

On the basis of the investigations of Lancefield and others, the opinion now is that the antigens of the haemolytic streptococci are arranged in an inner and an outer layer. Inside is the group-antigen $\mathrm{C}$ (apparently a complex polysaccharide). Outermost are the type-antigens $\mathbf{M}$ and T. $\mathbf{M}$ is a nucleoproteid digestible by trypsin. The presence of the antigen $T$, which is also supposed to be a polysaccharide, is perhaps rather more uncertain. According to my present view, after a period of between ten and fifteen hours' growth in the special broth the streptococci develop a "capsular substance" with antigenic properties and of an extremely labile character. (This antigen might be labelled $Y$.) If the bacteria 
TABLE 6

\begin{tabular}{|c|c|}
\hline Washing test with $0.9 \% \mathrm{NaCl}$ & $\begin{array}{l}\text { Agglutination with serum from } \\
\text { patient with rheumatoid arthritis }\end{array}$ \\
\hline $\begin{array}{l}\text { Unwashed living culture } \\
\text { Living culture washed once } . . \\
\text { Living culture washed } 5 \text { times }\end{array}$ & $\begin{array}{l}33322100 \\
11000000 \\
00000000\end{array}$ \\
\hline
\end{tabular}

grow too quickly or too long, it is destroyed. Washing experiments show its extreme lability (Table 6). The originally living culture gives a strong positive reaction with a serum from a patient with rheumatoid arthritis; but after being - washed once and five times in 0.9 per cent. saline, the reaction falls off distinctly, or perhaps disappears.

This serological reaction is of value to our understanding of the aetiology of rheumatoid arthritis. If the reaction is specific (and as yet there is nothing to argue that it is not), it means that haemolytic streptococci play a dominating aetiological role, although it is most probable that there are other aetiological factors in the very complex picture which rheumatoid arthritis presents. We cannot completely explain this affection solely as a simple chronic infection by haemolytic streptococci.

In addition, the reaction brings to light certain interesting points of resemblance between rheumatic fever and rheumatoid arthritis. Several earlier authors have averred that these diseases are related, but this theory only now finds a more tangible basis.

Presumably the agglutination test may also be of some importance in the diagnosis of rheumatoid arthritis. A positive reaction will support the clinical diagnosis, and a negative one should induce the clinician to reconsider it. In suspected cases, where the reaction is negative, the test should be repeated at regular intervals (say once a month). If it changes from negative to positive, the diagnosis is assured. The reaction may also be of some value in cases that are difficult to diagnose (mixed cases of arthritis and arthrosis, atypical polyarthritis or rheumatic fever, vague pains in the finger joints, etc.). Here, as with all other serological reactions, the clinician should remember, however, that a negative reaction does not definitely preclude the disease, and that a positive reaction merely supports the clinical diagnosis.

\section{Summary}

Earlier investigations of the agglutination test with streptococci are referred to. The author's own technique is described. Among 241 rheumatoid arthritis patients the agglutination test was positive in about 80 per cent. Among 900 control patients it was positive in only a very low percentage of cases. The immunobiology of the reaction is discussed, and the hypothesis advanced that the reaction is an expression of chronic infection by haemolytic streptococci and is induced by a labile surface antigen $(\mathrm{Y})$. 


\section{REFERENCES}

Angevine, D. Murray, Rothbard, S., and Cecil, R. L. (1942). Annals of Rheumatic Diseases, $3,101$.

Cecil, R. L., Nicholls, E. E., and Stainsby, W. J. (1931). Amer. J. med. Sci., 12, 181.

- and de Gara, P. F. (1946). Ibid., 211, 472.

Dawson, M. H., Olmstead, M., and Boots, R. H. (1932). J. Immunol., 187, 23. and Jost, E. L., (1934). Ibid., 355, 27. (1936). Nord. Med., 12, 1408.

Edström, G., and Winblad, S. (1947). Ibid., 33, 506.

Gray, J. W., and Gowen, C. H. (1931). Amer. J. med. Sci., 182, 682.

Goldie, W. (1938). Lancet, 2, 246.

Hedlund, P. (1947). Nord. Med., 33, 461.

Kalbak, K. (1944). Ibid., 22, 1156.

(1946). Ibid., 31, 1997.

Keefer, G. S., Myers, W. K., and Oppel, T. W. (1933). J. clin. Invest., 12, 267.

McEwen, C., Alexander, R. C., and Chasis, H. (1935). Proc. Soc. exp. Biol., N.Y., 33, 133.

Packalén, T.'(1943). Nord. Med., 17, 99.

Thulin, K. E. (1947). Ibid., 33, 508.

\section{THE ACUTE RHEUMATISM REGULATIONS, 1947}

As from 1st October, when the Acute Rheumatism Regulations, 1947, came into force in certain areas, all cases of acute rheumatism, including valvular heart disease arising from rheumatism, that occur among children under 16 have to be notified to the local medical officer of health. The districts to which the Regulations, made by the Minister of Health under the Public Health Act, 1936, apply are Bristol, Grimsby, Lincoln, Sheffield, and the administrative County of Lindsey (Lincolnshire). Designed to secure information which may aid in the prevention, early recognition, and adequate treatment of rheumatic heart disease and other types of acute rheumatism, the legislation will remain in force for the next three years. 